that it is secure and not likely to be broken. Also the mirror glass can be detached without disturbing the metal shield.

One small difficulty arose in the use of the device. When the beam from the lamp was exactly centred in the mirror, it was found that the shield cut out the focused rays when they met at the position of the shield. This difficulty was overcome by slightly decentering the lamp, so that the beam when exactly focused on the mirror impinged upon it to one side of the drilled hole. This decentering has no drawback. Messrs. Rayner, of New Bond Street, have fitted this shield to the new electric ophthalmoscope made by them for me, and which was described in your issue of February, 1932. The device is a real advantage, and it will be the standard pattern. It has been fitted to other instruments and has effected a great improvement in each case.

\title{
ANNOTATION
}

\section{Fishy Vision}

An interesting article, under the above heading, is contributed to the Fishing Gazette of February 20, 1932, by M. S. Mayou, who is a keen fisherman as well as an ophthalmic surgeon, and is thereby doubly qualified to write on this subject. His paper is an admirable exposition which is addressed principally to those fishermen who have no special knowledge of how sight is conducted, but it will not fail to interest the ophthalmic surgeon also. Fish do not have to rely on visual impressions entirely, as cutaneous sensations tell them their position in the stream, the strength of the current and the presence of obstacles such as weed and stones. The cutaneous nerve endings link up with ganglia along the lateral line on either side of the fish, and with a highly developed auditory system.

In investigating the visual powers of fresh-water fish three lines of approach may be used : first, observations on what a fish appears to see; second, the anatomical structure of the fish's eye, optic tracts and brain as compared with those of mammals; and thirdly, the experimentally placing one's own eye under water and estimating from what one sees how much a fish can see. The third method is wholly unreliable, as the eyes and brain of a fish are not constructed as in the human.

Mayou has experimented with perch in a tank. He found that when bits of worm were dropped into the tank without a splash between the fish and the daylight, they were secured by the fish every time; if, on the other hand, the bit was dropped between the 
fish and a tall bush which shadowed the other side of the tank, it as often as not fell to the bottom without being secured. There was no stream in the tank, and the perch mostly lay with their heads facing the light and their tails to the dark side. It would appear that it is the object coming between the fish and the light which enables the fish to see things rapidly.

Towards the end of last year he examined a number of freshwater fish with a luminous retinoscope, and found that fish out of water, as is usually described, are myopic, but when the eyes are covered with water they are either emmetropic or hypermetropic. $\mathrm{He}$ points out also that the light and movement senses are very acute in fish, but that their form sense is poor.

The fish's field is a panoramic one. Fishermen know that " the size and dressing, heavy or light to resemble the natural animal is far more important than the colour." With regard to colour vision fish live for the most part in monochromatic surroundings. Mayou considers it unlikely that the trout has colour vision, though it has a good discrimination of shades. He points out that a human being with good colour vision cannot tell the colour details of a fly situated between the eyes and the sky overhead.

Mayou's excellent article should do much to refute popular errors with regard to the vision of fishes, and in a piscatorial annotation we may not inaptly quote the remarks of Sir Thomas Browne on Lampreys in the third book of his Pseudodoxia; that great disperser of errors.

"Whether Lampries have nine eyes, as is received, we durst refer it unto Polyphemus, who had but one, to judge it. An error concerning eyes, occasioned by the error of eyes; deduced from the appearance of diverse cavities or holes on either side, which some call eyes that carelessly behold them; and is not only refutable by experience, but also repugnant unto Reason. For beside the monstrosity they fasten unto Nature, in contriving many eyes, who hath made but two unto any Animal, that is, one of each side, according to the division of the brain; it were a superfluous inartificial act to place and settle so many in one plane; for the two extreams would sufficiently perform the office of sight without the help of the intermediate eyes, and behold as much as all seven joyned together. For the visible base of the object would be defined by these two; and the middle eyes, although they behold the same thing, yet could they not behold so much thereof as these; so were it no advantage unto man to have a third eye between those two he hath already; and the fiction of Argus seems more reasonable than this; for though he had many eyes, yet were they placed in circumference and positions of advantage, and so are they placed in several lines in Spiders." 